Note

\section{Purification and Properties of a New L-Fucose-specific Lectin Produced by Streptomyces No. 100-2}

\author{
Ikuo Matsui, Toshiyuki Kameyama, \\ Kunio OISHI and Ko AIDA \\ Institute of Applied Microbiology, \\ The University of Tokyo, 1-1-1 Yayoi, \\ Bunkyo-ku, Tokyo 113, Japan
}

Received October 9, 1981

A group of lectins of particular interest is that of $\mathrm{L}$ fucose-specific ones, because $\mathrm{L}$-fucose is contained in the human blood group determinants and in certain glycoconjugates that play important roles in cell physiology. ${ }^{1,2)}$ Kameyama and others of our laboratory have found this type of lectin in the culture broth of a strain of Streptomyces. ${ }^{3)}$ Since then, it was demonstrated that the productivity of L-fucose-specific lectins was widely distributed in Streptomyces. Up to present, 7 lectins were obtained and purified from the culture broths of Streptomyces ${ }^{3 \sim 5)}$ and, except for one lectin, ${ }^{5)}$ all of them were proved to be L-fucose-specific. These Streptomyces Lfucose-specific lectins showed a quite similar specificity to each other for the sugars other than L-fucose. ${ }^{4)}$ Recently, we have found a new Streptomyces L-fucose-specific lectin, of which sugar specificity was uncommon. The present paper will describe the purification and the properties of this lectin, SFL 100-2.

The producer, Streptomyces No. 100-2, was isolated from soil in Kanto District in 1980 and has maintained in our laboratory. This organism was inoculated into a $0.05 \mathrm{M}$ phosphate buffer ( $\mathrm{pH} 7.0$ ) containing lactose $2 \%$, pepton $0.5 \%$, yeast extract $0.1 \%$, and $\mathrm{MgSO}_{4} \cdot 7 \mathrm{H}_{2} \mathrm{O}$ $0.05 \%$, and cultured at $27^{\circ} \mathrm{C}$ for 4 days with shaking. Cells were removed from the broth by centrifugation at $10,000 \times g$. To 10 liters of the supernatant thus obtained was added about $100 \mathrm{ml}$ of L-fucose-starch affinity adsorbent ${ }^{3)}$ and the mixture was stirred overnight at $4{ }^{\circ} \mathrm{C}$. The adsorbent gel was collected by decantation, poured into a column (diameter, $4 \mathrm{~cm}$ ), washed with $25 \mathrm{~mm}$ phosphate buffer $(\mathrm{pH} 7.0)$ until unadsorbed protein was completely removed, and then eluted with $0.2 \mathrm{M}$ D-mannose. Hemagglutinating activity of the eluates was assayed as described previously. ${ }^{3)}$ Active fractions were collected, treated once again in the same manner as above, and applied to a Sephacryl S-300 column $(2.8 \times 100 \mathrm{~cm})$. Hemagglutinating activity with specific activity of $1.3 \times 10^{4} \mathrm{HAU} / \mathrm{mg}$ protein was obtained as a single symmetrical peak at void volume.

Gel electrophoretic profiles of the purified preparation

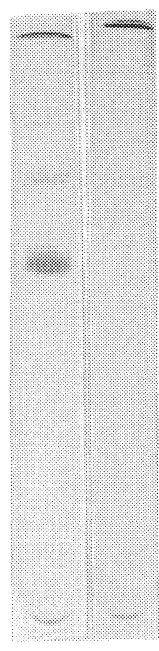

a

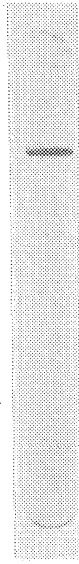

C

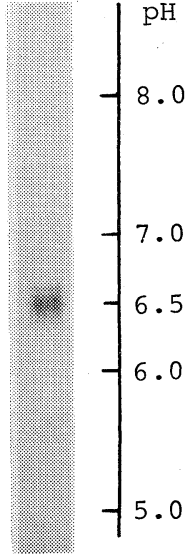

d
FIG. 1. Electrophoretic Profiles of SFL 100-2.

Sodium dodesyl sulfate-polyacrylamide gel electrophoresis on $5 \%$ gel at pH 7.2 with $5 \%$ mercaptoethanol (a) and without mercaptoethanol (b), disc gel electrophoresis on $3.8 \%$ gel at $\mathrm{pH} 9.5$ without mercaptoethanol (c), and isoelectric focusing electrophoresis on $1 \%$ agarose gel (d).

of this lectin are shown in Fig. 1. A major and two minor protein bands were detected on polyacrylamide gel electrophoresized at $\mathrm{pH} 7.2$ in the presence of sodium dodesyl sulfate (SDS) and 2-mercaptoethanol (ME) (Fig. 1-a). When ME was omitted, however, a single protein band was observed which moved scarcely from the origin of the gel (Fig. 1-b). As all the Streptomyces L-fucose-specific lectins so far examined had not self-aggregated in the presence of SDS, this is the first observation to show the importance of $\mathrm{ME}$ for the structure of these lectins. Molecular weight of the major and minor bands was calculated to be about $60,000,120,000$, and 180,000 , respectively, on $5 \%$ and $10 \%$ gels. The latter two were presumed to be the dimer and trimer of the former. Therefore minimum molecular weight of SFL 100-2 will be about 60,000. On disc gel electrophoresis at $\mathrm{pH} 8.9$, protein band could scarcely enter running gel (Fig. 1-c). Isoelectric focusing on agarose gel gave a single protein band and the isoelectric point of the protein was calculated to be 6.5 (Fig. 1-d).

Amino acid composition of SFL 100-2 is summarized in Table I. Duplicated samples of the lectin were hydrolyzed in $6 \mathrm{~N} \mathrm{HCl}$ for 24,48 , and $72 \mathrm{hr}$ at $110^{\circ} \mathrm{C}$ and applied to Hitachi Model 835 amino acid analyzer. According to the data obtained, there was no large difference between SFL 100-2 and other Streptomyces L-fucose-specific lectins. It is noteworthy, however, that SFL 100-2 contained 6 moles of half cystine/mole of protein. So far examined, presence of cysteine in other Streptomyces L-fucose-specific lectins 
TABle I. Amino Acid Composition of SFLs 100-2, 16-3 AND 485

\begin{tabular}{lccc}
\hline & SFL $100-2$ & SFL 16-3 & SFL $485^{a}$ \\
\cline { 2 - 4 } Amino acid & \multicolumn{3}{c}{ No. of amino acid residue/ } \\
mol protein & \\
\cline { 2 - 4 } AsX & 61 & 68 & 71 \\
Thr & $69^{c}$ & 90 & 89 \\
Ser & $33^{c}$ & 37 & 33 \\
G1X & 41 & 54 & 52 \\
Pro & 42 & 50 & 52 \\
Gly & 71 & 71 & 74 \\
Ala & 75 & 83 & 82 \\
1/2 Cys & $6^{d}$ & - & -75 \\
Val & 48 & 78 & 75 \\
Met & 3 & 4 & 3 \\
Ile & 16 & 6 & 7 \\
Leu & 42 & 52 & 50 \\
Tyr & $15^{c}$ & 12 & 12 \\
Phe & 15 & 18 & 19 \\
Lys & 15 & 7 & 8 \\
His & 5 & 10 & 7 \\
Arg & 29 & 31 & 35 \\
Trp & $6^{e}$ & 10 & 9 \\
\hline Molecular weight & 60,000 & 70,000 & 70,000 \\
\hline
\end{tabular}

a Data from ref. 4.

$b$ The values were calculated by assuming that the content of Pro in SFLs 100-2, 16-3 and 485 was 42 , 50 and $52 \mathrm{~mol} / \mathrm{mol}$ protein, respectively.

c Extrapolated value to zero hydrolysis time.

d Determined as cysteic acid.

e Estimated by the method of Edelhoch. ${ }^{6)}$

was not detected. ${ }^{4)}$ Cysteine residues in SFL 100-2 molecule must be concerned with self-aggregation of the lectin, because the lectin's band on SDS polyacrylamide gel electrophoresis could enter the running gel only when ME was present in the system.

Hemagglutinating activity of SFL 100-2 and its blood group and sugar specificities were examined by using the purified preparation described above. Hemagglutinationinhibition tests were made as described previously. ${ }^{3)} \mathrm{SFL}$ 100-2 agglutinated human blood group O, B, and A erythrocytes strongly in this order. Relative agglutinability of $\mathrm{O}, \mathrm{B}$, and A cells was 4,2, and 1, respectively, which is quite similar to the values of other Streptomyces L-fucosespecific lectins. ${ }^{4)}$ Sugar specificity of SFL 100-2 also resemble that of these lectins. Table 2 shows the sugar specificity of SFLs 100-2 and 16-3. Among the monosaccharides tested, L-fucose and D-mannose inhibited both lectins in the similar manner. Inhibition by D-fructose, Darabinose, and D-glucose was very weak or not detected. The most distinct characteristic of SFL 100-2 was that it was strikingly inhibited by tragacanthic acid. The acid
TAble II. Sugar Specificity of SFLs 100-2 AND 16-3

\begin{tabular}{|c|c|c|}
\hline \multirow{2}{*}{$\begin{array}{l}\text { Inhibitory } \\
\text { sugar }\end{array}$} & \multicolumn{2}{|c|}{$\begin{array}{l}\text { Minimum inhibitory } \\
\text { dose (mM) }\end{array}$} \\
\hline & SFL 100-2 & SFL 16-3 \\
\hline L-Fucose & 12.5 & 2.5 \\
\hline D-Mannose & 50 & 9.5 \\
\hline D-Fructose & $>200$ & 37.0 \\
\hline D-Arabinose & $>200$ & 44.3 \\
\hline D-Glucose & $>200$ & $>93$ \\
\hline$p$-Nitrophenyl $\alpha$-L-fucoside & 10 & 2.8 \\
\hline$p$-Nitrophenyl $\beta$-L-fucoside & 2 & 0.46 \\
\hline Tragacanthic acid & $0.49^{a}$ & $830^{a}$ \\
\hline Guar gum & $>250^{a}$ & $>6800^{a}$ \\
\hline Locust bean gum & $>250^{a}$ & $>6800^{a}$ \\
\hline Yeast mannan & $>250^{a}$ & $>10000^{a}$ \\
\hline
\end{tabular}

${ }^{a} \mu \mathrm{g} / \mathrm{ml}$.

used was prepared from gum tragacanth powder (Kanto Chemical Co., Inc., Tokyo) by cetyltrimethylammonium bromide precipitation $^{7)}$ and contained galacturonic acid, galactose, fucose, xylose, and arabinose in $\mathrm{mol} \%$ of 39,14 , 9, 33, and 5, respectively. Data in the paper of Kameyama and others ${ }^{3)}$ and of our re-examination showed that the minimal inhibitory dose of tragacanthic acid against SFL $100-2$ was as little as $0.49 \mu \mathrm{g} / \mathrm{ml}$. This value means that a molar SFL 100-2 was bound to tragacanthic acid corresponding to $60 \alpha$-L-fucosyl residues at the side chain terminals and that the inhibition of SFL 100-2 was 2,000 times as strong as that of SFL 16-3. Such a heavy inhibition by tragacanthic acid has not yet demonstrated in plant and animal lectins. ${ }^{8 \sim 11)}$ In this point, SFL 100-2 could be expected as an unprecedented probe for the studies on structure and biological activity of various Lfucose-containing glycoconjugates.

Acknowledgments. We would express our thanks to Dr. Y. Nagata of our institute and to Dr. J. Kurisaki of the Department of Agriculture, The University of Tokyo for amino acid analysis. This work was supported in part by a Grant-in-Aid (No. 347107) for Scientific Research from the Ministry of Education, Science and Culture of Japan and by a grant from the Kaiun Mishima Memorial Foundation, Tokyo (1979).

\section{REFERENCES}

1) G. M. McKibbon, J. Lipid Res., 19, 131 (1978).

2) P. Vischer and W. Reutter, Eur. J. Biochem., 84, 363 (1978).

3) T. Kameyama, K. Oishi and K. Aida, Biochim. Biophys. Acta, 587, 407 (1979).

4) T. Kameyama, F. Ishikawa, K. Oishi and K. Aida, 
Agric. Biol. Chem., submitted.

5) Y. Fujita, K. Oishi and K. Aida, Biochem. Biophys. Res. Commun., 53, 495 (1973).

6) H. Edelhoch, Biochemistry, 6, 1948 (1967).

7) G. O. Aspinall and J. Baillie, J. Chem. Soc., 1702 (1963).

8) G. F. Springer and P. Williams, Biochem. J., 85, 282
(1962).

9) G. F. Springer, T. Takahashi, P. R. Desai and B. J. Kolecki, Biochemistry, 4, 2099 (1965).

10) M. E. A. Pereira and E. A. Kabat, Biochemistry, 13, 3184 (1974).

11) I. Matsumoto and T. Osawa, Vox Sang., 21, 548 (1971). 